childhood: analysis of 15 patients diagnosed at less than 4 years of age. Am J Cardiol 1983;52:353-8.

${ }^{2}$ Boucek RJ, Noble NL, Gunja-Smith Z, Butler WT. The Marfan syndrome: a deficiency in chemically stable collagen cross-links. N Engl J Med 1981;305:988-91.

${ }^{3}$ Phornphutkul C, Rosenthal A, Nadas AS. Cardiac manifestations of Marfan syndrome in infancy and childhood. Circulation 1973;XLVII:587-96.
${ }^{4}$ Hohn AR, Webb HM. Cardiac studies of infant twins with Marfan's syndrome. Am J Dis Child 1971;122:526-8.

5 Edwards RH. Congenital Marfan's syndrome. Birth Defects 1975;XI:329-31.

Correspondence to Dr R Buchanan, Department of Pathology, St Mary's Hospital, Portsmouth.

Received 5 July 1985

\title{
Neonatal inferior vena cava and renal venous thrombosis treated by thrombectomy and nephrectomy
}

\author{
A G B CLARK, A SAUNDERS, M BEWICK, G HAYCOCK, AND C CHANTLER \\ Evelina Children's Hospital, Guy's Hospital, London
}

SUMMARY Neonatal inferior vena cava and renal venous thrombosis with obstruction was diagnosed clinically and confirmed by ultrasonography. Successful thrombectomy and nephrectomy were performed at $\mathbf{4 0}$ hours of age. Thrombus with obstruction occluding the inferior vena cava favours immediate surgery.

Renal venous thrombosis occurring in the neonate causes haematuria, oliguria, acute renal failure, and hypertension. ${ }^{1}$ Diagnosis is usually made on clinical grounds and supported by intravenous urography. ${ }^{2}$ Recent advances in ultrasonography have improved the ease of diagnosis, in most cases giving precise information on the location and extent of the thrombus. ${ }^{3}$ This directly influences management as shown by the case below.

\section{Case report}

Clinical details. This boy was born to a mother who had previously had two successful pregnancies producing live infants and one miscarriage at 10 weeks' gestation. After a normal pregnancy, spontaneous labour occurred at 39 weeks' gestation. During the first and second stages, meconium stained liquor was present but no other evidence of fetal distress was noted. The infant was born by vaginal delivery and his Apgar scores were 6 at one minute, 8 at five minutes, and 9 at 10 minutes. His birthweight was $3.55 \mathrm{~kg}$, and there was a true knot in the umbilical cord.

At 22 hours of age he was noted to have macroscopic haematuria, and by 30 hours, oedematous lower limbs, grunting respirations, a fine generalised purpuric rash, and bilaterally palpable kidneys. The systolic blood pressure was 130 to 140 $\mathrm{mm} \mathrm{Hg}$. Investigations showed a haemoglobin concentration of $15 \mathrm{~g} / \mathrm{dl}$, the total white cell count was $27.2 \times 10^{9} / 1$, platelets $25.0 \times 10^{9} / 1$, prothrombin time 17 seconds (control 13), partial thromboplastin time 62 seconds (control 35), thrombin time 25 seconds (control 10), and fibrin degradation products were greater than 10 but less than 40 . The plasma sodium concentration was $134 \mathrm{mmol} / \mathrm{l}$, potassium $4.5 \mathrm{mmol} / \mathrm{l}$, bicarbonate $15 \mathrm{mmol} / \mathrm{l}$, urea $6.6 \mathrm{mmol} / \mathrm{l}$, and creatinine $230 \mu \mathrm{mol} / \mathrm{l}$. Urinary electrolytes values were sodium $109 \mathrm{mmol} / \mathrm{l}$ and urea $22 \mathrm{mmol} / \mathrm{l}$.

After transfer to our unit at 37 hours of age, an abdominal ultrasound scan showed two large echogenic kidneys with no evidence of obstruction and an empty bladder. A thrombus $3 \mathrm{~cm}$ in length was seen in the inferior vena cava totally occluding the lumen of the vessel at the level of the renal veins but the latter were not visualised (Figure).

Management. The metabolic acidosis was corrected by intravenous administration of $4 \mathrm{mmol}$ of sodium bicarbonate. A laparotomy was performed at 40 hours of age. Operative findings were a large black right kidney and a large dusky left kidney. Both renal veins and the vena cava from below the renal vein orifices to the hepatic vein orifice were occluded by thrombus. A longitudinal venotomy allowed complete removal of the organising clot from the vena cava, and thrombectomy of the left renal vein was successful, with improvement in kidney size and colour. A similar procedure on the right renal vein failed to produce any improvement in the kidney's appearance, so a right nephrectomy was performed. A Tenkchoff peritoneal dialysis catheter was left in situ.

After operation a bolus of $150 \mathrm{U}$ of heparin followed by an infusion of $10 \mathrm{U} / \mathrm{kg}$ per $\mathrm{hr}$ intravenously was given for 22 days. A $99 \mathrm{~m}$-Tc 

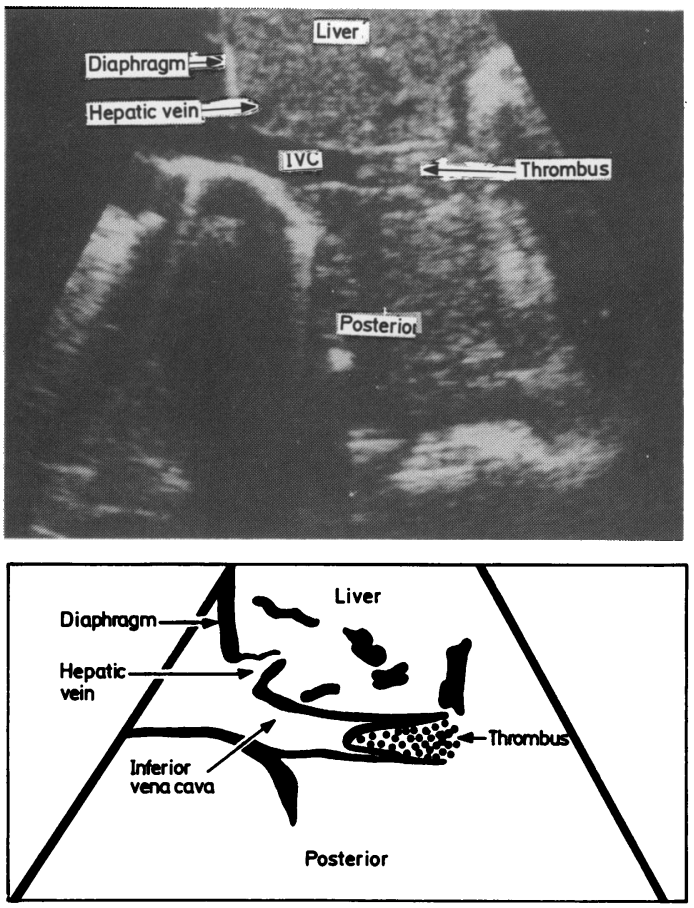

Figure Longitudinal abdominal ultrasound scan showing a clot obstructing the inferior vena cava (IVC).

diethylene triamine pentacetate (DTPA) scan at 3 days of age showed moderate perfusion of the remaining kidney with no evidence of function or excretion, consistent with acute tubular necrosis. Repeat ultrasound examinations at 3 and 16 days of age failed to show any evidence of thrombus. Peritoneal dialysis continued for 11 days and the peritoneal catheter was removed at 19 days of age.

On discharge from hospital, aged 24 days, the patient's plasma sodium concentration was 139 $\mathrm{mmol} / \mathrm{l}$, potassium $5.0 \mathrm{mmol} / \mathrm{l}$, urea $4.3 \mathrm{mmol} / \mathrm{l}$ and creatinine $168 \mu \mathrm{mol} / \mathrm{l}$. At follow up, aged 4 months, the plasma creatinine concentration was $104 \mu \mathrm{mol} / \mathrm{l}$ and the electrolytes, calcium, and phosphate values were normal. A DTPA isotope scan showed a normally functioning left kidney. The baby remained normotensive and well grown. Currently, at age 9 months, the plasma creatinine value has fallen to $55 \mu \mathrm{mol} / \mathrm{l}$, the Cr-EDTA clearance is $42 \mathrm{ml} / \mathrm{min}$ per $1.73 \mathrm{~m}^{2}$, and a left kidney dimercaptosuccinic acid (DMSA) isotope scan shows scars at the lateral aspect of the upper and lower poles.

\section{Discussion}

Most newborns with bilateral, renal venous throm- bosis die. A successful outcome has been reported with supportive management ${ }^{2}$ and after peritoneal dialysis, ${ }^{4}$ but in these cases obstruction of the inferior vena cava was not known to have occurred. Survival after thrombectomy has been recorded. ${ }^{5}$

We decided to perform a thrombectomy because of the presence of vena cava thrombosis with obstruction, believing there was little chance of survival without severe renal damage with conservative treatment. Indeed, only one case of survival after vena cava and bilateral renal venous thrombosis with non-surgical management has been recorded (confirmed by intravenous pyelography and inferior vena cavagraphy). ${ }^{6}$ At 7 months of age this infant was hypertensive (130 to $106 \mathrm{~mm} \mathrm{Hg}$, systolic), had a non-functioning right kidney, and a blood urea nitrogen value of 34 to $38 \mathrm{mg} / \mathrm{dl}(12.1$ to 13.5 $\mathrm{mmol} / \mathrm{l})$.

The appearance and size of the two kidneys in our patient, together with the absence of renal calcification, suggest that the thrombosis occurred perinatally. We could not determine whether the thrombosis was initially unilateral as all the clot found at laparotomy seemed to be of similar age and consistency.

Ultrasonography may be used to visualise the inferior vena cava without the attendant risks of hyperosmolar contrast media. If doubt exists whether the clot occludes the vena cava, obstruction may be determined by the failure of bubbles to pass along the vessel after rapid injection of saline into a lower limb intravenous cannula. Presence of a clot occluding the inferior vena cava, with obstruction to flow, favours immediate surgical intervention whereas renal venous thrombosis without vena cava obstruction may be managed conservatively.

\section{References}

1 Arneil GC, MacDonald AM, Sweet EM. Renal venous thrombosis. Clin Nephrol 1973;1:119-31.

2 Rasoulpour M, Mclean RH. Renal venous thrombosis in neonates; initial and follow up abnormalities. Am J Dis Child 1980;134:276-9.

${ }^{3}$ Rosenberg ER, Trought WS, Kirks DR, Sumner TE, Grossman $\mathrm{H}$. Ultrasonic diagnosis of renal venous thrombosis in neonates. Am J Radiol 1980;134:35-8.

${ }^{4}$ Counahan R. Bilateral renal venous thrombosis. Recovery after peritoneal dialysis. Arch Dis Child 1974;49:68-70.

5 Lowry MF, Mann JR, Abrams LD, Chance GW. Thrombectomy for renal venous thrombosis in an infant of diabetic mother. Br Med J 1970;iii:687.

${ }^{6}$ Seeler RA, Kapadia P, Moncado R. Non-surgical management of thrombosis of bilateral renal vein and inferior vena cava in a newborn infant. Clin Pediatr (Phila) 1970;9:543-7.

Correspondence to Professor C Chantler, Department of Paediatric Nephrology, Evelina Children's Hospital, Guy's Hospital, London SE1.

Received 31 May 1985 